\title{
$\nabla$ Assessment of Parent Satisfaction with Phlebotomy Services at a Paediatric Hospital in East Delhi
}

\author{
IJCRR \\ Section: Healthcare \\ ISI Impact Factor \\ (2019-20): 1.628 \\ IC Value (2019): 90.81 \\ $\operatorname{SJIF}(2020)=7.893$ \\ (c) (7) (8) \\ Copyright@IJCRR
}

\section{Arti Khatri ${ }^{1}$, Shikha Sharma*2}

'Assistant Professor, Department of Pathology, CNBC Hospital, New Delhi, India; ${ }^{2}$ Assistant Professor, Department of Biochemistry, CNBC Hospital, New Delhi, India.

\section{ABSTRACT}

Introduction: The phlebotomy service is the most common segment of the laboratory involved in direct patient contact. Satisfaction surveys are considered as reliable and valid tools for assessing the quality of medical care in the hospital. Given their childhood status, their parents are considered consumers of health care and thus represent the views of the patients. Data is scant regarding patient satisfaction with phlebotomy services, especially from a paediatric hospital.

Objective: The aim of the present study was therefore to assess the parent satisfaction of phlebotomy services in a paediatric hospital of East Delhi.

Methods: A total of randomly selected 265 outpatient guardians were interviewed by a 15-point predesigned questionnaire.

Results: The overall satisfaction of patients towards hospital-based pre-laboratory services was satisfactory (86\%). Concerning the environment of the phlebotomy room patients were relatively satisfied with the cleanliness of the blood drawing area, waiting time to get blood drawn and privacy during blood drawing. On the contrary, they were dissatisfied with the toilet accessibility and availability along with toilet cleanliness and comfort. Among the phlebotomy services rendered by the laboratory, patients were relatively satisfied with the number of needle stick attempts during blood drawing, availability of laboratory tests and courtesy/ respect of the phlebotomist. On the contrary, patients were highly dissatisfied with the availability of blood drawing room to put things and information provision about the bruise. Educational status was also significantly associated with the satisfaction rate of the respondents.

Conclusion: Hospital administration and the laboratory department should strive more to enhance patients' satisfaction, particularly in sanitation and location of the toilets in the hospital. Regular in-house training of phlebotomist focusing more on communication skills should be inculcated.

Key Words: Phlebotomy, Customer satisfaction, Children, Survey, Quality tool, Dissatisfaction

\section{INTRODUCTION}

The phlebotomy service is the most common segment of the laboratory involved in direct patient contact. Patients may perceive the level of care they receive during separate phases of the phlebotomy to reflect the quality of care provided by the laboratory or hospital. ${ }^{1}$ The paediatric phlebotomist faces challenges and is responsible for performing an invasive procedure on one of the largest and most vulnerable age groups that can cause long-term negative effects, including fear and avoidance of healthcare as an adult. ${ }^{2}$ Studies have shown that young children and infants who experience frequent painful medical events have escalated pain sensitivity, maladaptive pain responses, and needle phobias that contribute to an increasing needle-phobic society. ${ }^{3-5}$ Due to these concerns the phlebotomy staff must be extra careful while dealing with patients who must be made comfortable before pricking. This requires the phlebotomist to be humble; able to answer all patient queries and can collect the sample in one prick with minimal discomfort. Long waiting time, poor communication, repeated pricks, bruising and other negative experiences may influence patient's perception of care. ${ }^{1}$ Patient satisfaction has been defined as the degree of congruency between a patient's expectations of ideal care and his/her perception of the real care(s) he receives. ${ }^{6}$ An important aspect for evaluating health services involves the measurement

\section{Corresponding Author:}

Dr. Shikha Sharma, Assistant Professor Biochemistry, CNBC Hospital, New Delhi, India.

Email: drshikhacnbc@gmail.com

ISSN: 2231-2196 (Print)

Received: 23.09 .2020
ISSN: 0975-5241 (Online)

Revised: 14.11 .2020
Accepted: 19.01 .2021
Published: 04.06 .2021 
of patient satisfaction rates. A mismatch between the patient expectation and the service they receive leads to dissatisfaction. Monitoring patient satisfaction is an important and useful quality improvement tool for clinical laboratories in particular and health care organizations ${ }^{7}$ and is also required by laboratories to maintain their accreditations. ${ }^{8}$ The quality standards laid down by the National Accreditation Board of Hospitals (NABH) have also emphasized the patient's role in the improvement of laboratory services. Some important key indicators have been indicated by NABH which include waiting time for phlebotomy service to monitor the management, process and outcome especially patient satisfaction which are used as tools for continual improvement. Patient satisfaction surveys have been considered as reliable and valid tools for assessing the quality of medical care in the hospital considering the paediatric age group. ${ }^{9}$ Given their childhood status, their parents are considered as consumers of health care and thus represent the views of the patients. ${ }^{10}$ Satisfaction surveys can be conducted by various methods which include phone surveys, written surveys, group discussions or personal interviews. These surveys provide us satisfaction ratings. ${ }^{11}$ These ratings can help us to find weak areas such as lack of universal safety precautions, long waiting time, cleanliness of facility, location of the laboratory, toilet accessibility and availability, maintenance of privacy and confidentiality, the cost of the laboratory service etc. These were some of the reasons for patient's satisfaction related to clinical laboratory services as found in a few previous studies. ${ }^{1,12-16}$ The present study was therefore designed to find out satisfaction ratings along with deficient areas causing dissatisfactions among patients requiring phlebotomy services. There are very few studies that relate to patient behaviour and satisfaction from developing countries, as compared to the high volume of publications from developed countries. To the best of our knowledge, this is one of the first studies to assess parent satisfaction of phlebotomy services in a paediatric hospital. Considering these lacunae, the present study was therefore planned to assess the parent satisfaction of phlebotomy services in a paediatric tertiary care hospital.

\section{MATERIALS AND METHODS}

The present cross-sectional study was carried out at Chacha Nehru Bal Chikitsalaya Hospital located in East Delhi from May to July 2020. Parents of children attending the Outpatient Department with phlebotomy services of Chacha Nehru Bal Chikitsalaya Hospital were the study population. Inclusion Criteria: -Parents of outpatients up to 12 years of age and requested for clinical chemistry, haematology and serology were included in the study. Exclusion Criteria: - Parents of patients referred or advised to the Intensive care unit or emergency with acute or chronic illness were excluded from the study since they are considered to be exceptional circumstances. The study was planned as a questionnaire-based survey; the study provided an insight into various problems faced by parents bringing their children to the hospital and their satisfaction rate.

\section{Sample size}

Sample size was calculated for each specific objective to get the maximum using a single population for objective one. The largest sample size for the patients was determined by using a single population formula considering the following assumptions: proportion of customer's satisfaction $94 \%$ (taken from a previous study made on a patient's laboratory perception at the selected government hospital in East Delhi) ${ }^{17}$ level of significance $=0.05$, margin of error $(d)=3 \%$ and a non-respondent rate of $10 \%$. Therefore, 265 patients were included in the study.

The following formula was used for calculating the sample size:

$\mathrm{n}=(\mathrm{Z} \alpha / 2)^{2} \mathrm{P}(1-\mathrm{P}) / \mathrm{d}^{2}$

Where:-

$\mathbf{n}=$ the desired sample size

$\mathbf{P}=$ Assuming patient satisfaction on clinical laboratories at East Delhi $=94 \%$

$\mathbf{Z} \boldsymbol{\alpha} / \mathbf{2}=$ Critical value at $95 \%$ confidence level of certainty (1.96)

$\mathbf{d}=$ Assuming the margin of error between the sample and the population $=3 \%$

The calculated result is 241 and the total sample size required for the study with a non-response rate of $10 \%$ was found to be $\mathbf{2 6 5}$.

\section{Sampling Method}

The probability sampling method was utilized for the study. Every $4^{\text {th }}$ parent was interviewed. This process was continued till the required sample size was collected.

\section{Tools of data collection}

Data was collected by using a structured, pre-tested and interviewer-administered questionnaire initially prepared in English and then translated to local language Hindi. The Hindi versions of the questionnaire were used for data collection. Data was collected by 6 trained data entry operators. Besides their socio-demographic characteristics, study participants were asked to rate each aspect of the phlebotomy service.

The scoring was done by the typical five-level Likert scale:

Score (1-5):- Poor-1, Fair-2, Good-3, Very good-4, Excellent $-5$ 


\section{Data Quality Assurance}

All the participants were asked to fill a questionnaire in the survey. These questionnaires were developed after referring to a validated published survey tool from the CAP Q Probes program..$^{18}$ The patient's questionnaire was translated to Hindi and some questions were rephrased. The adaptation was done after ten persons from Chacha Nehru Bal Chikitsalya $\mathrm{CNBC}$ had validated and piloted the questionnaires. Parents of children undergoing phlebotomy were selected randomly and they were asked to give their feedback. Written informed consent was obtained from all the participants before they participated in the study after informing them about the objectives of the study.

\section{Data Analysis and Interpretation}

An appropriate statistical technique/method was used for data analysis. Descriptive parameters were presented as numbers and percentages. The poor and fair response was considered as dissatisfied whereas good, very good and excellent responses were considered as satisfied. The percentage of satisfaction or dissatisfaction was estimated by dividing the number of satisfied or dissatisfied responses by the total number of responses. The overall rate of satisfaction based on the Likert scale score was calculated as follows: $($ No. of poor rating $\times 1)+($ No. of good rating $\times 2)+($ No. of average rating $\times 3)+($ No. of very good rating $\times 4)+($ No. of excellent rating $\times 5$ ) divided by the total number of ratings (1- 5)for the specific laboratory service. Internal consistency was checked using Cronbach's alpha coefficient and it has found to be 0.884 (Cronbach's alpha coefficient $>0.7$ is acceptable). Verbal and written consent was also obtained from the study participants before administering the questionnaire. The response of respondents was anonymous and data collectors informed respondents that they had full right to discontinue or refuse to participate in the study.

\section{RESULTS}

A total of 265 subjects were included in the present study with a response rate of $100 \%$. The mean $( \pm \mathrm{SD})$ age of the children was $7.3 \pm 5.2$ years ranging from 1 month to 12 years. The male: female sex ratio was $1.45: 1$. On evaluating the educational status of the parents it was observed that the majority $32.8 \%(\mathrm{~N}=87)$ had primary education as shown in Table 1 . On assessing the overall satisfaction of phlebotomy services $86 \%$ of the respondents were satisfied with the services they got, whereas $14 \%$ were dissatisfied with the phlebotomy services as shown in Figure 1. Figure 2 shows the evaluation of satisfaction rates of different parameters concerning the environment of the phlebotomy room. The highest three dissatisfaction rates were observed for the following parameters toilet accessibility and availability $38.1 \%$, toilet cleanliness and comfort with a rate of $35.8 \%$ and comfort of chairs with a dissatisfaction rate of $15.1 \%$ respectively. Figure 3 shows the evaluation of satisfaction rates of different parameters concerning the phlebotomy process. The highest dissatisfaction rates were observed for the availability of the parameters of space in the blood drawing room to put things with a rate of $25.3 \%$ followed by information provision about bruise with a dissatisfaction rate of $16.9 \%$. In Likert Scale, the overall mean rate of satisfaction of parents at CNBC Hospital for phlebotomy services was 3.49 out of a possible of 5 . The mean rate of satisfaction for different aspects of phlebotomy ranged from 2.89 to 3.98 . The lowest mean rating of satisfaction concerning the environment of the phlebotomy room was for toilet accessibility and availability and toilet cleanness and comfort with a mean rating of 2.89 and 3.01, respectively. Whereas the lowest mean rating concerning the phlebotomy process was for availability of place in the blood drawing room to put things and information provision about bruise with a mean rating of 3.15 and 3.36 respectively. The overall mean satisfaction score for phlebotomy services in the present study was 3.61 as shown in Table 2 . There was no statistically significant association between gender and overall satisfaction rate $(\mathrm{p}=0.052)$ (Table 3$)$. But still, a slight difference was observed amongst the females who seemed to be more satisfied as compared to males (Figure 4). Still, the difference was not enough to cause any significant association with gender for the phlebotomy services to evaluate the satisfaction rate. Chi-square analysis was done to evaluate whether the level of patient's satisfaction had a relationship with explanatory variables. The analysis showed no significant relationship between gender and age towards phlebotomy services $(p>0.05)$. However, there was a significant relationship between educational status and level of patients' satisfaction $(\mathrm{p}<0.0001)$. Furthermore, a significant relationship was also obtained between waiting time for specimen collection, No. of needle stick attempts, information about the bruise, availability of a place to put things, availability of required laboratory tests and satisfaction for phlebotomy services $(\mathrm{p}<0.0001)$ as shown in Table No. 3 .

\section{DISCUSSION}

The present study was set out with the aim of assessing the satisfaction of parents towards phlebotomy services at Chacha Nehru Bal Chikitsalya (CNBC) paediatric tertiary care hospital in East Delhi, India. The present study revealed that the overall client satisfaction level with the phlebotomy services was $86 \%$ that showed a vast majority of the respondents were satisfied with almost all aspects of the phlebotomy services they received at the hospital. A possible explanation for the increased satisfaction maybe because of the confidentiality observed by the laboratory staff in this study as patient issues are meant to be kept secret by the staff of health facilities. This rule is accepted worldwide and guides the opera- 
tions of all health providers, irrespective of job description or location. Our findings were under that observed Institute of Human Behaviour and Allied Sciences (IHBAS), Delhi ${ }^{17}$ who had a satisfaction rate of $94 \%$ and at Rama Medical College and Research Center (RMCH and RC) Ghaziabad who found $69 \%$ of the phlebotomy services to be good and $24 \%$ satisfactory. ${ }^{1}$ The mean overall satisfaction score in our study ranged between 2.5 and 4.7 out of 5 . Concerning the environment of the phlebotomy room, the majority of our respondents were relatively satisfied with the cleanliness of the blood drawing area $(95.9 \%)$. The importance of laboratory environment for sample collection and laboratory services has been researched in many studies. Contrary to our findings a major dissatisfaction amongst patients regarding environmental hygiene has been observed in several studies. ${ }^{19-21}$ This finding speaks volumes as health facilities are meant to provide health care as well as promote health amongst patients. A high satisfaction rate was also observed concerning waiting time to get blood drawn $(90.6 \%)$. Waiting time for phlebotomy is also a key indicator covered under NABH continual quality improvement. Our high value may be because of the HIMS (Hospital Information Management System) installed at our hospital which is mostly not available in another government hospital in Delhi or Eastern UP. Our findings were in accordance to studies conducted by Teklemariam et $\mathrm{al}^{20}$ and Pathak et al..$^{22}$ On the contrary this parameter received a low scoring in other studies. ${ }^{17,23}$ Satisfaction with the patient waiting time in this study is commendable as it has a positive implication on the continuous utilisation of health care services by the patients. Amongst the different services rendered by the laboratory highest satisfaction rate was observed for the number of needle stick attempts and availability of laboratory tests with a satisfaction rate of $93.9 \%$ each. Pathak et $\mathrm{al}^{22}$ in their study also demonstrated similar findings where $83.5 \%$ of the respondents at the laboratory expressed their satisfaction with the technical competence of the laboratory staff. Similar findings were also reported in other studies. ${ }^{1,17,24}$ Our high value may not be out of place as; our hospital is a tertiary health care centre that is well equipped and manned with highly trained and competent technical staff. Moreover, being a paediatric hospital, the phlebotomists are extra trained in the careful handling of anxious and aggrieved children along with their parents. Likewise, most of the respondents in our study were also satisfied with the availability of required tests to be done in the laboratory. In tandem with these are findings documented in other studies. ${ }^{1,22,24,25}$ These findings are welcoming as they promote appropriate health-seeking behaviour amongst the population. A majority (91.6\%) of the respondents in our study were also satisfied with the courtesy and respect showed by the laboratory staff. This finding is consistent with other studies on patient satisfaction with laboratory services..$^{1,17,21,26}$ The finding is not surprising as health care workers are expected to be compassionate while discharging their duties. Moreover, we being paediatric hospital child and our parents have to be handled courteously and professionally to avoid any grievance. Concerning the environment of the phlebotomy room, our respondents were dissatisfied with mainly the toilet accessibility, availability and cleanliness (38.1\% and $35.8 \%$ respectively). Availability and cleanliness of toilets have been a shared problem observed in many other studies. ${ }^{119-21}$ These findings could be due to low attention given for activities out of the laboratory examination room. Concerning the phlebotomy process, a higher dissatisfaction rate was also observed concerning space availability to put things in the phlebotomy room. Patients who report no place available to put things are more dissatisfied with laboratory services as compared to their counterparts. This is comparable with a study conducted in Ethiopia. ${ }^{7}$ The absence of a place in the laboratory examination room might lead patients to think about probable misplacing of their belongings leading to decrease satisfaction with the services they receive. A high rate of dissatisfaction was also observed regarding information about bruise (16.9\%). Similar findings were also found in another study where only $37 \%$ of the responders found the service to be very good. ${ }^{1}$ Phlebotomist should undergo regular on the job pieces of training along with continuing education. They should also be trained to be good communicators to provide adequate quality care to their patients. Findings from this study showed that the degree of satisfaction was not statistically different by age or by sex of the child. In comparison with this contradictory result, findings were documented in some other studies conducted among patients utilising laboratories. ${ }^{21,27-29}$ Educational status was also statistically associated with parent satisfaction in our study. Similar findings showing that the patients' educational status influenced the satisfaction rate with the health care service received at the laboratory were reported in some studies. ${ }^{21,30}$ This probably points to the impact education has on the decision-making ability of individuals as well as the improved and better understanding associated with being well educated. Contrasting findings were however reported in some other surveys. ${ }^{27-29}$

\section{STRENGTH AND LIMITATIONS OF THE STUDY}

The strength of the study included a relatively high number of indicators that were employed to determine the overall patients' satisfaction towards phlebotomy services (it had fifteen indicators). Also, relatively larger sample size and study participants were included compared with other previous Indian studies. The study had some limitations in that it did not assess the laboratory personnel awareness of patients' need. Also, face-to-face interview of respondents may have exposed the study to social desirability bias. 


\section{CONCLUSION}

The present study showed that the current status of the overall satisfaction of patients towards hospital-based pre-laboratory services was satisfactory. This was from the fact that out of the 265 respondents $86 \%$ of the parents were satisfied with the phlebotomy services. Hospital administration and the laboratory department should strive more to enhance patients' satisfaction, particularly in sanitation and the location of the toilets in the hospital. Regular in-house training of phlebotomist along with that communication skills should also be advocated. Further studies can be planned on a larger sample size with the inclusion of clinical laboratory parameters to further enhance the study. Regular surveys should be advocated at regular intervals for continuous quality improvement.

\section{RECOMMENDATIONS}

- Patient comfort in the blood drawing room and toilet should be improved by assuring patients privacy during conducting phlebotomy procedures and maintaining the cleanliness of the toilet by sensitizing the workers in the sanitation department.

- Adequate space for placing belongings during phlebotomy should also be ensured by hospital administration.

- The provision of relevant information to patients also needs improvement. This can be done by improving the communication skills of the phlebotomy staff by providing regular training.

- Patient waiting time (waiting time to give laboratory specimen, waiting time to get laboratory results and waiting time to get registration services) should be reduced. This can be implemented by upgrading Laboratory Information System LIS and appointing more staff which will provide an extra edge of expertise.

- Phlebotomists should participate in regular educational competency assessments, both written and observational, which allow them to recognize and overcome errors.

- Periodic patients' satisfaction survey should be institutionalized at frequent intervals to provide feedback for continuous quality improvement.

- Based on the finding, dissatisfaction of patients towards phlebotomy services could be a possible factor for the lower rate of patients' satisfaction towards clinical and laboratory services. Therefore, the hospital administration should work together in improving the rate of patients' satisfaction towards phlebotomy services. By doing so, the satisfaction rate of clinical and laboratory services could be improved.

\section{ACKNOWLEDGEMENT}

The authors are grateful to all the patients and their parents who participated in this study. The authors also thank the hospital authorities for their cooperation.

FUNDING: All of the authors are responsible for the funding of the study without the involvement of grant, scholarship, sponsorship, or any other resources of funding.

CONFLICT OF INTEREST: The author reports no conflicts of interest in this work.

ETHICS CONSIDERATION: Ethical clearance No.54/5966/IEC/CNBC has approved this study from the Ethics Committee of Chacha Nehru Bal Chikitsalya Hospital, New Delhi before the study being conducted.

AUTHOR CONTRIBUTION: All of the authors are equally contributed to the study from the conceptual framework, data gathering, data analysis, until reporting the results of the study.

\section{REFERENCES}

1. Dawar R. Patient satisfaction of phlebotomy services in a tertiary care hospital. Int J Curr Res Aca Rev. 2015;3(6):35-38.

2. Young KD. Pediatric procedural pain. Ann Emerg Med. 2005;45:160 -71.

3. Buskila D, Neumann L, Zmora E, Feldman M, Bolotin A, Press J. Pain sensitivity in prematurely born adolescents. Arch Pediatr Adolesc Med. 2003; 157:1079 - 82.

4. Moadad N, Kozman K, Shahine R, Ohanian S, Badr LK. Distraction using the buzzy for children during an IV insertion. J Pediatr Nurs. 2016;31:64-72.

5. Kennedy RM, Luhmann J, Zempsky WT. Clinical implications of unmanaged needle-insertion pain and distress in children. Paediatrics. 2008;122(3):130 -3.

6. Qadri SS, Pathak R, Singh M, Ahluwalia SK, Saini S, Garg PK. An assessment of patient's satisfaction with services obtained from a tertiary care hospital in rural Haryana. Intern J Collabo Res Internal Med Pub Health. 2012;4(8):1524-1537.

7. Abera RG, Abota BA, Legese MH, Negesso AE. Patient satisfaction with clinical laboratory services at TikurAnbessa specialized hospital, Addis Ababa, Ethiopia. Patient Pref Adher. 2017;11:1181-1188.

8. Georgieva E, Tsankova G, Kaludova V, Ermenlieva N. Patients' satisfaction with laboratory services at selected medical diagnostic laboratories in Varna. J IMAB. 2014; 20(2):500-501.

9. Torres J, Guo KL. Quality improvement techniques to improve patient satisfaction. Int J Health Care Qual Assur Inc Leadersh Health Serv. 2004; 17:334-338.

10. Otani K, Kurts RS, Buroughs TE, Waterman B. Reconsidering models of patient's satisfaction and behavioural intentions. Health care Manag Rev. 2003; 28:7-14.

11. Oja PI, Kouri TT, Pakarinen AJ. From customer satisfaction survey to corrective actions in laboratory services in a university hospital. Int J Qual Health Care. 2006; 18(6):422-28.

12. Howanitz PJ, Cembrowski GS, BachnerP. Laboratory phlebotomy. College of American Pathologists Q-Probe study of patient satisfaction and complications in 23,783 patients. Arch Pathol Lab Med. 1991;115:867-72. 
13. Mindaye T and Taye B. Patients' satisfaction with laboratory services at antiretroviral therapy clinics in public hospitals, Addis Ababa, Ethiopia. BMC Res Notes. 2012;5:184.

14. Geletta T, Eyasu E, Mikias D, Shibabew A, Keneni E. Patients Satisfaction on Clinical Laboratory Services at Nekemte, Referral Hospital, Oromia Ethiopia. Food Sci Qual Manag. 2014;30.

15. Getachew R, Arka B, Hailu M and Edao A. Patient satisfaction with clinical laboratory services at TikurAnbessa specialized hospital, Addis Ababa, Ethiopia. Patient Pref Adher. 2017;11.

16. Zelalem T, Abiyu M, Haji K, and Getachew K. Clients and clinician satisfaction with laboratory services at selected government hospitals in eastern Ethiopia; BMC Res Notes 2013; 6:15.

17. Gupta A, Dwivedi T, Sadhana, Chaudhary R. Analysis of Patient's Satisfaction with Phlebotomy Services in NABH Accredited Neuropsychiatric Hospital: An Effective Tool for Improvement. J Clin Diagn Res. 2017;11(9):5-8.

18. College of American Pathologists: Laboratory accreditation program. Laboratory general checklist. Northfield GEN. 2011;20335:1-129.

19. Bhargava A, Thakur A, Mishra B, Taneja J, Dogra V, Loomba P (2012). Patient satisfaction survey of microbiological tests done in G.B. Pant Hospital. Inter J Health Care Qual Assu; 25(7): 555-564.

20. Teklemariam Z, Mekonnen A, Kedir H, Kabew G. Clients and clinician satisfaction with laboratory services at selected government hospitals in eastern Ethiopia. BMC Res Notes 2013;6(15):1-7.

21. Million B, Seid A, Debela B, Derese D, Moges D, Misganaw B. HIV/AIDS patients satisfaction on ART laboratory service in selected Governmental Hospitals, Sidamma Zone, Southern Ethiopia. Sci J Public Health. 2013;1(2):85-90.

Table 1: Socio-demographic variables of study subjects at CNBC Hospital

\begin{tabular}{lcc} 
Variable & Frequency & Percent \\
Age of Child & & \\
$\leq 4$ years & 133 & 50.1 \\
$5-8$ & 80 & 30.2 \\
$\geq 9$ years & 52 & 19.6 \\
Sex of Child & & \\
Male & 157 & 59.2 \\
Female & 108 & 40.8 \\
Educational status of Parents & \\
Can't read or write & 63 & 23.7 \\
Primary Education & 87 & 32.8 \\
Secondary Education & 70 & 26.4 \\
College and above & 45 & 16.9 \\
\hline
\end{tabular}

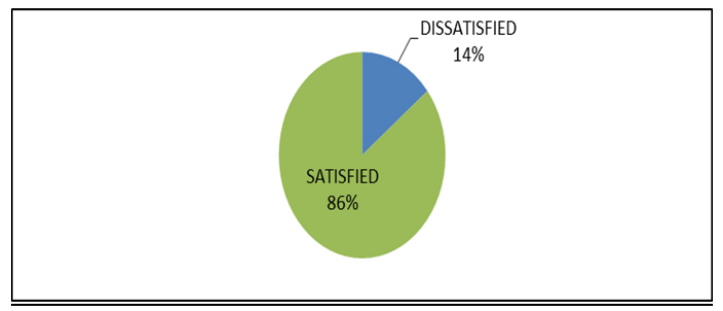

Figure 1: Overall Satisfaction with Phlebotomy Services at CNBC Hospital.
22. Pathak O, Taylor D, Kennedy MP, Virtue E, McDonald G. A multifaceted intervention improves patient satisfaction and perception of emergency department care. Int J Qual in Health Care. 2012;18(3): 238-45.

23. Oja PI, Kouri TT, Pakarinen AJ. From customer satisfaction survey to corrective actions in laboratory services in a university hospital. Int J Qual Health Care. 2006;18:422-8.

24. Adebasi YH, Ahmed MI. Patients' satisfaction with medical services in the Qassim Area. J Clin Diagn Res. 2011;5(4):813-817.

25. Iliyasu Z, Abubarka SI, Abubarka S, Lawan UM, Gajida AU. Patient's satisfaction with services obtained at the Aminu Kano Teaching Hospital, Kano, Northern Nigeria. Niger J Clin Pract. 2010;13(4):371-378.

26. Sodani PR and Sharma K. Assessing patient satisfaction for investigative services at public hospitals to improve quality of services. Ethiop J Health Dev. 2011;2(3):405-408.

27. Abdosh B. The Quality of hospital services in eastern Ethiopia: Patient's perspective. Ethiop J Health Dev. 2006;20(3):199-200.

28. Mekonnen A, Teklemariam Z, Kedir H, Kabew G. Patient Satisfaction with Laboratory Services in Selected Government Hospitals, Eastern Ethiopia. Harar Bull Health Sci. 2011;3:5-8.

29. Georgieva E, Tsankova G, Kaludova V, Ermenlieva N. Patients satisfaction with laboratory services at selected medical - diagnostic laboratories in Varna. J Integr Market Advis Board. 2014;20(2):500-501.

30. Fekadu A, Andualem M, Yohannes HM. Assessment of Clients' Satisfaction with Health Service Deliveries at Jimma University Specialized Hospital. Ethiop J Health Sci. 2011;21(2):101-9.

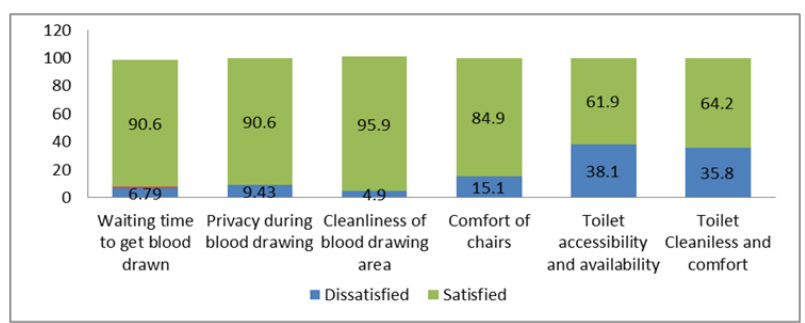

Figure 2: Satisfaction rates with respect to the environment of the phlebotomy room.

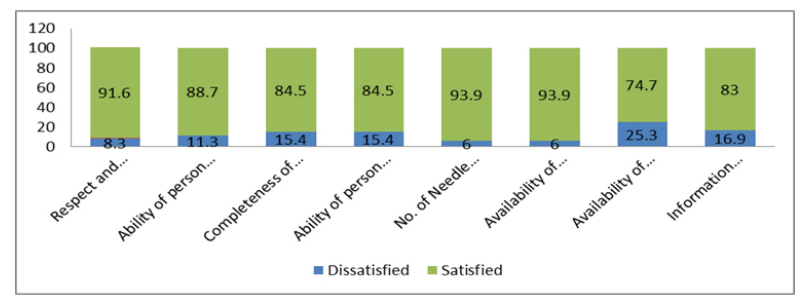

Figure 3: Satisfaction Rates concerning Phlebotomy Process.

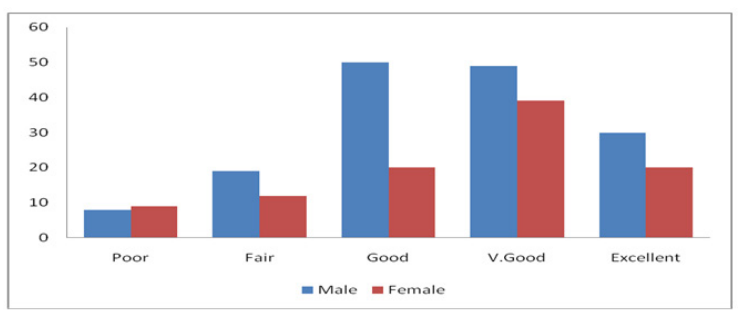

Figure 4: Overall Satisfaction Rates with Respect to Gender. 
Table 2: Rate of parent's satisfaction determined by mean \pm SD score of responses to different satisfaction questions

\begin{tabular}{|c|c|c|c|c|c|c|c|c|c|c|c|}
\hline \multirow[t]{2}{*}{ Variable } & \multicolumn{2}{|c|}{ Poor } & \multicolumn{2}{|c|}{ Fair } & \multicolumn{2}{|c|}{ Good } & \multicolumn{2}{|c|}{ Very Good } & \multicolumn{2}{|c|}{ Excellent } & \multirow[t]{2}{*}{$\operatorname{Mean} \pm \mathrm{SD}$} \\
\hline & $\mathbf{N}$ & $\%$ & $\mathbf{N}$ & $\%$ & $\mathbf{N}$ & $\%$ & $\mathbf{N}$ & $\%$ & $\mathbf{N}$ & $\%$ & \\
\hline $\begin{array}{l}\text { Waiting time to get blood drawing service } \\
\text { (In terms of }<10 \mathrm{~min}, 10-30 \mathrm{~min}>30 \mathrm{~min} \text { ) }\end{array}$ & 8 & 3 & 10 & $3 \cdot 7$ & 57 & 21.5 & 100 & 21.5 & 83 & 31.3 & $3.93 \pm 0.98$ \\
\hline Privacy during blood drawing & 5 & 1.9 & 20 & $7 \cdot 5$ & 72 & 27.1 & 108 & 40.7 & 60 & 22.6 & $3.74 \pm 0.95$ \\
\hline Cleanliness of blood drawing area & 6 & 2.2 & 7 & 2.6 & 116 & $43 \cdot 7$ & 81 & 30.6 & 55 & 20.7 & $3.64 \pm 0.91$ \\
\hline Respect and courtesy of the staff & 9 & $3 \cdot 3$ & 13 & $4 \cdot 9$ & 98 & 36.9 & 76 & 28.6 & 69 & 26 & $3.69 \pm 1.02$ \\
\hline $\begin{array}{l}\text { The ability of a person drawing blood to put } \\
\text { the client at ease. }\end{array}$ & 10 & 3.7 & 20 & $7 \cdot 5$ & 103 & 38.8 & 83 & 31.3 & 49 & 18.4 & $3.53 \pm 0.99$ \\
\hline Comfort of chairs & 10 & $3 \cdot 7$ & 30 & 11.3 & 120 & $45 \cdot 2$ & \multicolumn{2}{|c|}{7729} & \multicolumn{2}{|c|}{2810.5} & $3.46 \pm 0.87$ \\
\hline $\begin{array}{l}\text { Completeness of information on how and } \\
\text { when to receive test result }\end{array}$ & 19 & 7.1 & 22 & 8.3 & 106 & 40 & 54 & 20.3 & \multicolumn{2}{|c|}{6424.1} & $3.48 \pm 1.14$ \\
\hline $\begin{array}{l}\text { Ability of the person drawing blood to } \\
\text { answer question }\end{array}$ & 17 & 6.4 & 24 & 9.0 & 109 & 41.1 & 63 & 23.7 & 52 & 19.6 & $3.41 \pm 1.10$ \\
\hline Toilet accessibility and availability & 63 & 23.7 & 38 & $14 \cdot 3$ & 68 & 25.6 & 56 & 21.1 & \multicolumn{2}{|c|}{4015} & $2.89 \pm 1.38$ \\
\hline Toilet cleanness and comfort & 47 & $17 \cdot 7$ & 48 & 18.1 & 74 & $27 \cdot 9$ & 46 & $17 \cdot 3$ & \multicolumn{2}{|c|}{5018.9} & $3.01 \pm 1.35$ \\
\hline $\begin{array}{l}\text { Availability of place in blood drawing } \\
\text { room to put things }\end{array}$ & 32 & 12 & 35 & 13.2 & 107 & 40.4 & 43 & 16.2 & \multicolumn{2}{|c|}{4818.8} & $3.15 \pm 1.22$ \\
\hline Information provision about bruise & 15 & 5.6 & 30 & 11.3 & 110 & 41.5 & 63 & 23.7 & \multicolumn{2}{|c|}{$4717 \cdot 7$} & $3.36 \pm 1.08$ \\
\hline Availability of lab tests & 5 & 1.8 & 11 & 4.1 & 86 & 32.4 & \multicolumn{2}{|c|}{6926} & 94 & $35 \cdot 4$ & $3.65 \pm 0.95$ \\
\hline $\begin{array}{l}\text { Number of Needle stick attempts (1, } 2 \text { or } \\
\text { more) }\end{array}$ & 6 & 2.2 & 10 & $3 \cdot 7$ & 80 & 30.1 & 56 & 21.1 & 113 & 42.6 & $3.98 \pm 1.04$ \\
\hline Overall service satisfaction & 16 & 6.0 & 22 & 8.3 & 72 & 27.2 & 93 & 35.1 & 62 & 23.4 & $3.61 \pm 1.11$ \\
\hline
\end{tabular}

Table 3: Chi-square analysis for predictors of parent's satisfaction towards phlebotomy services $(\mathbf{n}=\mathbf{2 6} 5)$

Variable $\quad$ Satisfied (N, \%) $\quad$ Dissatisfied (N, \%) Chi-square (p-value)

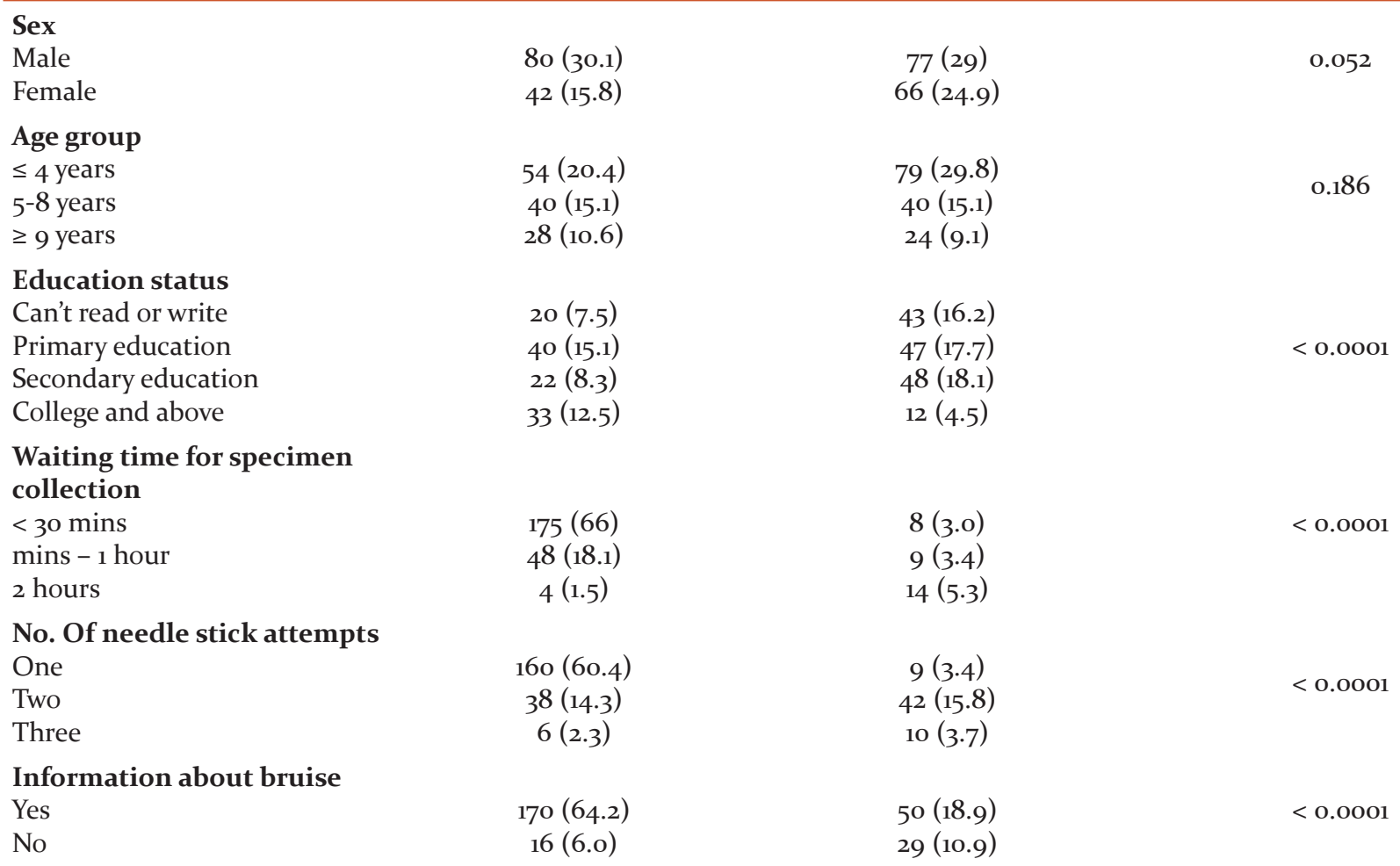


Table 3: (Continued)

\begin{tabular}{lccc} 
Variable & Satisfied (N, \%) & Dissatisfied (N, \%) & Chi-square (p-value) \\
$\begin{array}{l}\text { Availability of place to put } \\
\text { things }\end{array}$ & & & \\
Yes & $143(16.2)$ & $55(20.8)$ & $<0.0001$ \\
No & $20(7.5)$ & $47(17.7)$ & \\
$\begin{array}{l}\text { Availability of required labo- } \\
\text { ratory tests }\end{array}$ & & \\
Yes all & $209(78.9)$ & $40(15.1)$ & $<0.0001$ \\
Yes some only & $5(1.89)$ & $11(4.2)$ & \\
\hline
\end{tabular}

